\title{
Amphetamine, epinephrine, and glucose enhancement of memory retrieval
}

\author{
WILLIAM S. STONE, REBECCA J. RUDD, and PAUL E. GOLD \\ University of Virginia, Charlottesville, Virginia
}

\begin{abstract}
Amphetamine, epinephrine, and glucose enhance memory storage when administered shortly after training. Amphetamine enhancement of memory storage may be mediated by peripheral epinephrine actions, and epinephrine enhancement of memory storage may involve increases in blood glucose levels. Amphetamine and possibly epinephrine also enhance memory retrieval when administered shortly before testing. To examine the parallels in pharmacological enhancement of memory storage and retrieval, we tested the effects on memory of injections of amphetamine $(1.0 \mathrm{mg} / \mathrm{kg})$, epinephrine $(0.05 \mathrm{mg} / \mathrm{kg})$, or glucose $(100 \mathrm{mg} / \mathrm{kg})$ administered prior to retention tests in mice. Mice were trained in a one-trial inhibitory (passive) avoidance task. Thirty minutes prior to testing, each mouse received an injection of saline, amphetamine, epinephrine, or glucose. In a second experiment, rats were trained on a one-trial inhibitory avoidance task and were administered glucose $(100,250$, or $500 \mathrm{mg} / \mathrm{kg})$ prior to testing. The results indicate that amphetamine, epinephrine, and glucose all significantly enhanced learned performance, supporting the view that similar neuroendocrine systems may contribute to both memory storage and retrieval. In addition, these findings provide another demonstration that peripheral glucose injections modify behavior.
\end{abstract}

Memories are most susceptible to modification by treatments administered near the times of training or testing. When time-dependent effects on memory are observed with treatments administered during the posttraining period, the results suggest that modification of later retention performance is based on alterations of memory storage (Gold \& Zornetzer, 1983; McGaugh, 1983). When treatments administered shortly before testing enhance memory, the results suggest that the effects represent augmentation of memory retrieval (cf. Riccio \& Ebner, 1981; Sara, 1985; Spear, 1978).

Considerable evidence now supports the view that neuroendocrine responses to training regulate memory storage processing (Gold \& Zornetzer, 1983; McGaugh, 1989; McGaugh \& Gold, 1989). For example, ACTH and epinephrine enhance later retention performance when administered shortly after training. Both amphetamine and the peripherally acting 4-OH amphetamine also enhance memory if administered soon after training (Martinez, Jensen, et al., 1980). As with many treatments that affect memory storage, enhancement of memory storage through administration of amphetamine apparently requires participation of the adrenal medulla (Martinez, Vasquez, et al., 1980; cf. Gold, 1989), suggesting that amphetamine effects on memory storage may be medi-

Supported by research grants from the Office of Naval Research (N00014-85-K0472), the National Institute of Mental Health (MH 31141), and the American Diabetes Association, and by a National Research Service Award (AG 05408) to W. S. Stone. Address reprint requests to W. S. Stone, Department of Psychology, University of Virginia, Gilmer Hall, Charlottesville, VA 22903.

-Accepted by previous editor, Lynn Nadel ated by the release of epinephrine from the adrenal medulla. Recent findings suggest that epinephrine may regulate memory storage in part by means of the hormone's classic action to increase circulating glucose levels. For example, like epinephrine, posttraining glucose injections enhance memory storage (Gold, 1986; Gold, Vogt, \& Hall, 1986; Messier \& Destrade, 1988; Messier \& White, 1984), and posttraining circulating glucose levels predict later retention performance under several conditions (Hall \& Gold, 1986).

Studies of memory retrieval processes have included examinations of many of the same treatments. For instance, ACTH or amphetamine administration shortly before testing enhances retention performance under several behavioral tasks and attenuates the influence of natural forgetting or the administration of an amnestic treatment (see, e.g., Quartermain, 1982; Quartermain \& Altman, 1982; Quartermain, Judge, \& Friedman, 1983; Richardson, Riccio, \& Devine, 1984; Sara, 1984, 1985; Sara \& Deweer, 1982).

Previous studies of peripheral catecholamines and retrieval of learned inhibitory avoidance responses include reports that epinephrine both enhanced (Izquierdo \& Dias, 1983a) and did not enhance (Lzquierdo \& Dias, 1983b) retrieval processes when administered before testing to animals that had received only saline immediately after training. With the evidence that peripheral epinephrine enhances memory storage, mediates amphetamine effects on memory storage, and may itself be mediated by subsequent glucose release, in Experiment 1 we examined the hypothesis that epinephrine, amphetamine, and glucose would all similarly modify retention performance in mice if administered shortly before the time of testing. As a measure of the generality of these findings, in Ex- 
periment 2 we examined whether administration of glucose shortly before testing would also enhance retention performance in rats.

\section{EXPERIMENT 1}

\section{Method}

Subjects. Six-week-old male mice (DUB-ICR, Dominion Laboratories, Dublin, VA) were housed in groups of 4 and maintained on a 12:12-h light:dark schedule (lights on $0700 \mathrm{~h}$ ) with free access to food and water. Behavioral testing was performed between 1300 and $1700 \mathrm{~h}$.

Procedure. Epinephrine, amphetamine, and glucose were freshly prepared on each experimental day. All drugs were dissolved in saline and injected i.p. Epinephrine bitartrate and amphetamine sulfate were obtained from Sigma Chemical Company, and D-glucose was obtained from the J. T. Baker Chemical Company.

The mice were trained on a multitrial inhibitory (passive) avoidance task. The training apparatus was a two-compartment alley in which a lighted start compartment $(10 \times 14 \times 23 \mathrm{~cm})$ was separated from a larger dark compartment $(10 \times 14 \times 37 \mathrm{~cm})$ by a sliding door. The training procedure was modified from that of Altman, Stone, and Ogren (1987). At the beginning of each trial, the mouse was placed in the start compartment, the sliding door was opened, and the latency to enter the dark compartment (all 4 paws) was recorded. The mouse then received an escapable footshock $(0.11 \mathrm{~mA})$ through metal plates that constituted the floor of the alley. When the mouse reentered the lighted start compartment, the shock was turned off. Each mouse included in the experiment received a minimum of two and a maximum of four shocks. After receiving the second shock, training continued until the mouse did not reenter the dark compartment within $60 \mathrm{sec}$, at which time it was immediately removed from the apparatus, or until the maximum number of shocks was received. All mice included in the experiment showed latencies of $90 \mathrm{sec}$ or less to cross into the dark compartment on the initial trial (preshock), and they also showed latencies of $150 \mathrm{sec}$ or less to reenter the dark compartment after receiving the first shock.
Forty-eight hours after training, the mice were tested for retention of the avoidance behavior. The procedure was identical to that used on the training day, except that no shock was administered when the animals crossed over into the dark compartment. The latency to enter the dark compartment was recorded to a maximum of $600 \mathrm{sec}$. Thirty minutes prior to testing, groups of mice received injections of saline, glucose $(100 \mathrm{mg} / \mathrm{kg})$, epinephrine $(0.5 \mathrm{mg} / \mathrm{kg})$, or amphetamine $(1.0 \mathrm{mg} / \mathrm{kg})$. The doses were selected on the basis of previous experiments in which these drugs enhanced retention (Grold, 1986; Quartermain, 1982; Quartermain \& Altman, 1982; Stone, Croul, \& Gold, 1988). Comparisons between groups were performed using Mann-Whitney $U$ tests (two-tailed).

\section{Results}

As is demonstrated in Figure 1, glucose, epinephrine, and amphetamine all significantly enhanced retention, relative to the saline administered to the control group $(U s=36,33.5$, and 13.5 , respectively, $p s<.05)$. There were no significant differences between treatment groups.

\section{EXPERIMENT 2}

In Experiment 1, it was demonstrated that, like amphetamine and epinephrine, glucose enhanced memory retrieval in mice. In Experiment 2, we focused on whether or not glucose can also enhance retrieval in rats. In order to assess the generality of the effects of glucose further, a different procedure, which we have previously used to study pharmacological manipulations of inhibitory avoidance behavior (e.g, Gold, 1986; Gold et al., 1986), was used to assess retrieval processes in this experiment.

\section{Method}

Subjects. Male Sprague-Dawley rats (300-400 g, Dominion Laboratories, Dublin, VA) were used in Experiment 2. Prior to behavioral testing, the rats were placed on a restricted water regi-

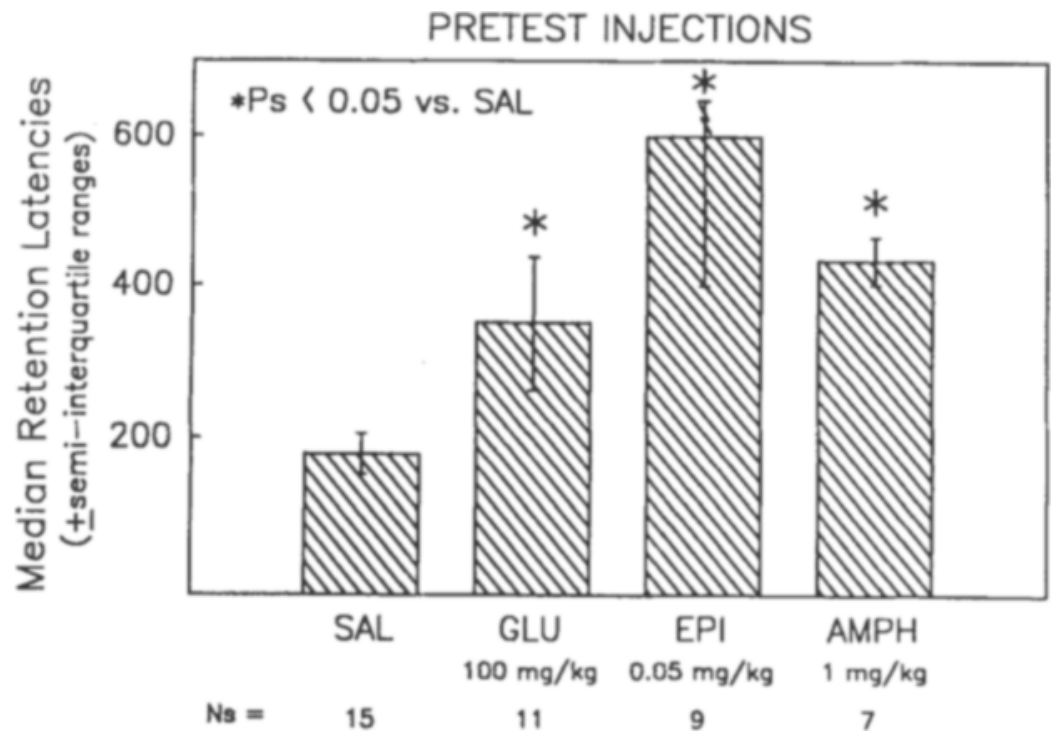

Figure 1. Retention performance of mice trained to criterion in a multitrial inhibitory avoidance task $(0.11 \mathrm{~mA})$ and tested for retention $48 \mathrm{~h}$ bater. Groups of mice that received glucose (100 mg/kg), epinephrine (0.05 mg/kg), or amphetamine $(1.0 \mathrm{mg} / \mathrm{kg}) 30 \mathrm{~min}$ prior to testing all demonstrated significantly higher retention latencies than did a saline control group. 


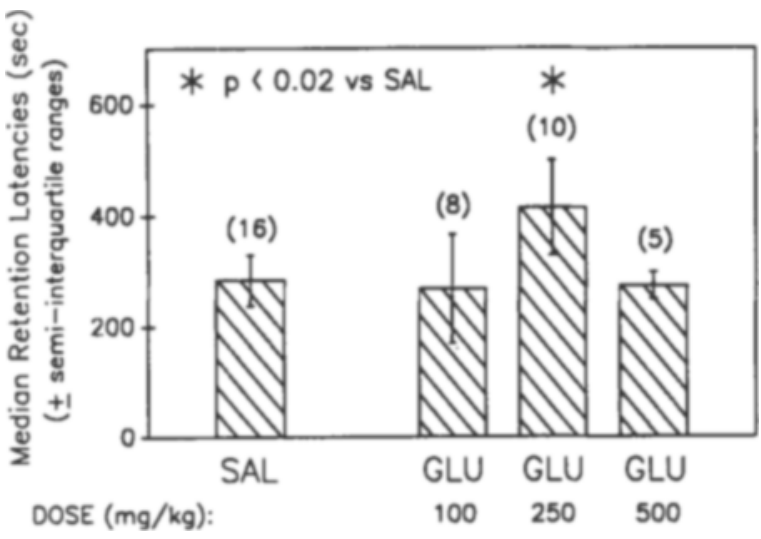

Figure 2. Retention performance of rats trained and tested in an inhibitory avoidance task including a single footshock $(1.0 \mathrm{~mA}$, $0.7 \mathrm{sec}$ ); rats received an injection of saline or glucose $30 \mathrm{~min}$ prior to the test trial. Glucose $(250 \mathrm{mg} / \mathrm{kg})$ significantly enhanced retention above the value of the saline group. Note that the effects of glucose on retrieval followed an inverted-U dose-response curve.

men, which reduced and then maintained their body weight at $80 \%$ of the initial weight. The animals had free access to food.

Procedure. After the animals attained stable reduced weights, each animal received five pretraining trials (1/day) in an inhibitory avoidance apparatus. The training apparatus was a two-compartment alley, with a white start compartment $(10 \times 14 \times 23 \mathrm{~cm})$ separated by a sliding door from a black compartment $(10 \times 14 \times$ $37 \mathrm{~cm}$ ); the black compartment had a grid floor through which footshock could be administered.

During pretraining, the rats were allowed to approach and to drink from a water spout located at the end of the black compartment. On each trial, the rat was placed in the start compartment, the sliding door was opened, and the latency to drink and the amount of time spent drinking during the next $30 \mathrm{sec}$ were noted. By the fourth trial, each rat began to drink within $15 \mathrm{sec}$ after the door was opened and continued to drink for at least 20 of the allowed $30 \mathrm{sec}$.

Training occurred on the day after the last pretraining trial. Thirty minutes before training, groups of rats received injections (i.p.) of glucose $(100,250$, or $500 \mathrm{mg} / \mathrm{kg}$, dissolved in saline $)$ or saline. During the trial, the animals were allowed to drink as before but received a footshock $(1.0 \mathrm{~mA}, 0.7 \mathrm{sec})$ during the 10 th second of drinking. The rats were then immediately removed from the training apparatus and were returned to their home cages. Retention tests were administered $24 \mathrm{~h}$ after training. The latency to drink for a total of $30 \mathrm{sec}$ (maximum latency $=600 \mathrm{sec}$ ) was taken as the measure of retention performance. In other experiments, it has been demonstrated that this treatment does not itself affect performance if administered without training (Messier \& White, 1987).

Statistical comparisons were made between groups using the Mann-Whitney $U$ test (two-tailed).

\section{Results}

As is shown in Figure 2 , glucose $(250 \mathrm{mg} / \mathrm{kg})$ administered prior to testing significantly enhanced retention performance $(U=33, p<.02)$. The effects of glucose on retrieval followed an inverted-U dose-response curve.

\section{DISCUSSION}

The findings obtained here indicate that, like amphetamine, peripheral epinephrine and glucose enhance reten- tion performance when administered near the time of testing. Thus, these findings support the view that these treatments, which enhance memory storage processes, also enhance memory retrieval processes. In addition, despite differences in species and paradigms, the effects of glucose on retrieval were comparable for rats and for mice, thereby extending their generality.

Although the pharmacological bases for amphetamine effects on memory storage and retrieval may involve either central or peripheral catecholamine actions, circulating epinephrine does not readily enter the central nervous system (Axelrod, Weil-Malherbe, \& Tomchick, 1959), and it is thus not likely to be a direct agonist of central catecholamine function. Moreover, there is now substantial evidence that increases in circulating glucose levels contribute to epinephrine effects on memory storage (cf. Gold \& Stone, 1988; Stone, Manning, \& Gold, in press). The present findings suggest that similar mechanisms may also contribute to pharmacological enhancement of retrieval processes. However, it should also be noted that some actions of amphetamine that may contribute to its effects on retrieval, such as its effects on central dopaminergic systems (Quartermain, 1982), may not be shared by epinephrine and glucose.

Just as hormonal responses to training modulate memory storage, hormonal responses at the time of testing appear to modulate retrieval processes for the original experience. Two general ideas regarding this effect are that the neuroendocrine responses (here increases in circulating epinephrine and glucose) may augment the activity of neural systems responsible for retrieval of learned information, or that neuroendocrine treatments may provide internal contextual cues, reactivating old memories (Riccio \& Ebner, 1981; Sara, 1985; Spear, 1978). Both views, which are not mutually exclusive, might account for the enhanced retention observed here.

Izquierdo (1984) has suggested that similar neuroendocrine status at the times of training and testing may be important to optimal retention performance. The present results tend not to support this view. In previous studies, we found that training under conditions such as those used here elicits epinephrine or glucose responses during the immediate posttraining period that are small compared to those obtained after injections of epinephrine and glucose at the doses effective here (McCarty \& Gold, 1981; Hall \& Gold, 1986). Therefore, if a "match" between neuroendocrine states at the times of training and testing were important for retention performance, epinephrine and glucose injections prior to testing should impair rather than enhance retention performance. Still, optimal retention performance may be promoted by activation of neuroendocrine mechanisms at the time of both storage and retrieval (high at storage and retrieval times), but activation at either storage or retrieval (a high-low mismatch) still results in improved performance relative to low activation at either time.

In addition to demonstrating that epinephrine and glucose can enhance memory retrieval as well as storage processes, the results obtained here also add to the grow- 
ing list of glucose effects on brain and behavioral functions, which now includes interactions with cholinergic drugs on measures of activity, tremors, and sleep (cf. Gold \& Stone, 1988; Stone \& Gold, 1988; Stone et al., in press). Thus, increases in circulating glucose levels appear to have a wide range of neurobiological and behavioral effects.

\section{REFERENCES}

Altman, H. J., Stone, W. S., \& Ogren, S. O. (1987). Evidence for a possible functional interaction between serotonergic and cholinergic mechanisms in memory retrieval. Behavioral \& Neural Biology, 48, 49-62.

AXelrod, J., Weil-Malherbe, H., \& Tomchick, R. (1959). The physiological disposition of ${ }^{3} \mathrm{H}$-epinephrine and its metabolite metanephrine. Journal of Pharmacology \& Experimental Therapeutics, 127, 251-256.

GoLD, P. E. (1986). Glucose modulation of memory storage processing. Behavioral \& Neural Biology, 45, 342-349.

GoLD, P. E. (1989). Neurobiological features common to memory modulation by many treatments. Animal Learning \& Behavior, 17, 94-100.

Gold, P. E., \& STONE, W. S. (1988). Neuroendocrine factors in agerelated memory dysfunctions: Studies in animals and humans. Neurobiology of Aging, 9, 709-717.

Gold, P. E., VoGT, J., \& Hall, J. L. (1986). Glucose effects on memory: Behavioral and pharmacological characteristics. Behavioral \& Neural Biology, 46, 145-155.

Gold, P. E., \& ZoRNeTZER, S. F. (1983). The mnemon and its juices: Neuromodulation of memory processes. Behavioral \& Neural Biology, 38, 151-189.

HaLL, J. L., \& GoLd, P. E. (1986). The effects of footshock, epinephrine, and glucose injections on plasma glucose levels in rats. Behavioral \& Neural Biology, 46, 156-176.

IZQUIERDo, I. (1984). Endogenous state dependency: Memory depends on the relation between the neurohumoral and hormonal states present after training and at the time of testing. In G. S. Lynch, J. L. McGaugh, \& N. M. Weinberger (Eds.), Neurobiology of learning and memory (pp. 333-350). New York: Guilford.

IzQUIERDo, I., \& DiAs, R. D. (1983a). Memory as a state dependent phenomenon: Role of ACTH and epinephrine. Behavioral \& Neural Biology, 38, 144-149.

IzQuiERDo, I., \& DiAs, R. D. (1983b). Memory modulation by the administration of ACTH, adrenaline or B-endorphin after training or prior to testing in an inhibitory avoidance task in rats. Brazilian Joumal of Medical \& Biological Research, 16, 54-64.

Martinez, J. L., Jensen, R. A., Messing, R. B., Vasquez, B. J., Soumireu-Mourat, B., Gedes, D., Liang, K. C., \& McGaugh, J. L. (1980). Central and peripheral actions of amphetamine on memory storage. Brain Research, 182, 157-166.

Martinez, J. L., Vasquez, B. J, Rigter, H., Messing, R. B., JenSEN, R. A., Liang, K. C., \& MCGAugh, J. L. (1980). Attenuation of amphetamine-induced enhancement of learning of adrenal demedullation. Brain Research, 195, 433-443.

MCCARTY, R., \& Gold, P. E. (1981). Plasma catecholamines: Effects of footshock level and hormonal modulators of memory storage. Hormones \& Behavior, 15, 168-182.
McGaugh, J. L. (1983). Hormonal influences on memory. Annual Review of Psychology, 34, 297-323.

MCGAUGH, J. L. (1989). Involvement of hormonal and neuromodulatory systems in the regulation of memory storage. Annual Review of Neuroscience, 12, 255-287.

MCGAUGH, J. L., \& GoLD, P. E. (1989). Hormonal modulation of memory. In R. Brush \& S. Levine (Eds.), Psychoendocrinology (pp. 305-339). New York: Academic Press.

Messier, C., \& Destrade, C. (1988). Improvement of memory for an operant response by post-training glucose in mice. Behavioral Brain Research, 31, 185-191.

Messier, C., \& White, N. M. (1984). Contingent and non-contingent actions of sucrose and saccharin reinforcers: Effects on taste preferences and memory. Physiology \& Behavior, 32, 195-203.

Messier, C., \& WhITE, N. M. (1987). Memory improvement by glucose, fructose and two glucose analogs: A possible effect on peripheral glucose transport. Behavioral \& Neural Biology, 48, 104-127.

Quartermain, D. (1982). The role of catecholamines in memory processing. In J. A. Deutsch (Ed.), Physiological bases of memory (2nd ed., pp. 387-423). New York: Wiley.

Quatermain, D., \& Altman, H. J. (1982). Facilitation of retrieval by d-amphetamine following anisomycin-induced amnesia. Physiological Psychology, 10, 283-292.

Quartermain, D., Judge, M. E., Friedman, E. (1983). Role of lisuride and other dopamine agonists in memory retrieval processes. In D. B. Calne, R. Horowaski, R. J. McDonald, \& W. Wuttke (Eds.), Lisuride and other dopamine agonists (pp. 503-514). New York: Raven Press.

Riccio, D. C., \& Ebner, D. L. (1981). Postacquisition modifications of memory. In N. E. Spear \& R. R. Miller (Eds.), Information processing in animals: Memory mechanisms (pp. 291-317). Hillsdale, NJ: Erlbaum.

Richardson, R., Riccio, D. C., \& Devine, L. (1984). ACTH-induced recovery of extinguished avoidance responding. Physiological Psychology, 12, 184-192.

SARA, S. J. (1984). Forgetting of a conditioned emotional response and its alleviation by pretest amphetamine. Physiological Psychology, 12, 17-22.

SARA, S. J. (1985). Noradrenergic modulation of selective attention: Its role in memory retrieval. Annals of the New York Academy of Science, 444, 178-193.

SARA, S. J., \& DEWEER, B. (1982). Memory retrieval enhanced by amphetamine after a long retention interval. Behavioral \& Neural Biology, 36, 146-160.

SPEAR, N. E. (1978). The processing of memories: Forgetting and retention. Hillsdale, NJ: Erlbaum.

Stone, W. S., Croul, C. E., \& Gold, P. E. (1988). Attenuation of scopolamine-induced amnesia in mice. Psychopharmacology, 96, $417-420$.

Stone, W. S., \& Gold, P. E. (1988). Sleep and memory relationships in intact old and amnestic young rats. Neurobiology of Aging, 9, 719-727.

Stone, W. S., Manning, C. A., \& Gold, P. E. (in press). Relationships between circulating glucose levels and memory storage processes. In H. J. Altman \& B. Altman (Eds.), Alzheimer's and Parkinson's disease: Recent advances in research and clinical management. New York: Plenum.

(Manuscript received June 20, 1989;

revision accepted for publication February 14, 1990.) 